\title{
Terms of trade i wzrost gospodarczy w Polsce w okresie 1980-2009
}

\author{
Piotr Misztal*
}

Celem artykutu jest analiza oddziaływania zmian cenowych terms of trade i zmienności terms of trade na wzrost gospodarczy w Polsce w okresie 1980-2009. Wyniki badań przeprowadzonych za pomoca modelu wektorowej autoregresji (VAR) ujawnity, że poprawa cenowych terms of trade w Polsce prowadzita do wzrostu dynamiki PKB per capita, zaś wzrost zmienności cenowych terms of trade przyczyniat się do zmniejszenia tempa wzrostu PKB na mieszkańca $w$ Polsce. Ponadto potwierdzono stosunkowo większe oddziatywanie zmian cenowych terms of trade niz zmienności terms of trade na dynamikę wzrostu gospodarczego w Polsce. Wykazano również, że zmiana cenowych terms of trade i zmienność terms of trade wyjaśniaty $w$ zbliżonym stopniu zmienność PKB per capita w Polsce w okresie 1980-2009.

Slowa kluczowe: terms of trade, wzrost gospodarczy, model wektorowej autoregresji

Nadesłany: 28.12.2011 | Zaakceptowany do druku: 08.05.2012

\section{Terms of trade and economic growth in Poland in the period 1980-2009}

This article aims to analyze the impact of changes in terms of trade and terms of trade volatility on economic growth in Poland in the period 1980-2009. The results of tests using the vector autoregressive model (VAR) revealed that improved terms of trade in Poland led to increased dynamics of GDP per capita, while the increase in terms of trade volatility reduced the growth rate of GDP per capita in Poland. In addition, there was confirmed the greater impact of changes in terms of trade, than the terms of trade volatility on the dynamics of economic growth in Poland. It was also demonstrated that the change in terms of trade and volatility of terms of trade, explained in a similar degree the variation of GDP per capita in Poland in the period 1980-2009.

Keywords: terms of trade, economic growth, vector autoregressive model

Submitted: 28.12.2011 | Accepted: 08.05.2012

JEL: F43, F41, P33

* Prof. nadzw. Piotr Misztal - Uniwersytet Technologiczno-Humanistyczny w Radomiu Adres do korespondencji: Uniwersytet Technologiczno-Humanistyczny w Radomiu, Wydział Ekonomiczny, Katedra Biznesu i Finansów Międzynarodowych, ul. B. Chrobrego 31, 26-600 Radom, e-mail: p.misztal@pr.radom.pl. 


\section{Wprowadzenie}

Terms of trade określa się jako stosunek zmian ceny towarów eksportowanych do importowanych. Wskaźnik ten pokazuje zmiany siły nabywczej eksportu w stosunku do importu poszczególnych krajów. Poprawa terms of trade ma miejsce wtedy, gdy ceny towarów eksportowanych rosną szybciej lub maleją wolniej niż ceny towarów importowanych, zaś pogorszenie terms of trade występuje wtedy, gdy ceny towarów eksportowanych rosną wolniej lub maleją szybciej niż ceny towarów importowanych.

W literaturze ekonomicznej wskazuje się na trzy główne kanały transmisji szoku w postaci zmian cenowych terms of trade na wzrost gospodarczy. Mianowicie, zmiany cenowych terms of trade wywołują zmiany produktywności kapitału i zmiany rozmiarów inwestycji, co oddziałuje na dynamikę wzrostu gospodarczego. Ponadto zmiany cenowych terms of trade prowadzą do zmiany tempa wzrostu gospodarczego przez zmianę rozmiarów całkowitych oszczędności i konsumpcji w kraju. Wreszcie, zmiany cenowych terms of trade prowadzą do zmian rozmiarów wydatków publicznych, czego skutkiem jest zmiana salda budżetu państwa i w konsekwencji zmiana tempa wzrostu gospodarczego (rysunek 1).

Prebisch (1950) i Singer (1950) sugerowali, że w krajach rozwijających występuje tendencja spadkowa terms of trade w stosunku do krajów rozwiniętych gospodarczo. Prawidłowość ta zwana jest hipotezą Prebischa-Singera i dotyczy ona tego, że ceny towarów podstawowych wymienianych w skali międzynarodowej zmniejszają się w stosunku do cen towarów przemysłowych. Ponadto Prebisch (1959) stwierdził, że pogorszenie cenowych terms of trade w krajach rozwijajacych sie prowadzi do zmniejszenia dochodów i dobrobytu w tych krajach. Co więcej, Singer (1950) sugerował, że zmiany terms of trade w istotnym stopniu wpływają na dostępne środki finansowe w krajach słabo rozwiniętych gospodarczo, co oddziałuje na rozmiary inwestycji i w konsekwencji na tempo wzrostu gospodarczego tych krajów. Sytuacja ta jest konsekwencją tego, że zmiany wielkości handlu zagranicznego maja istotne znaczenie dla krajów słabo rozwiniętych, ponieważ dochody do dyspozycji i w ślad za tym rozmiary inwestycji zależą w dużym stopniu od wpływów eksportowych tych krajów.

Rysunek 1. Kanały wpływu cenowych terms of trade na wzrost gospodarczy

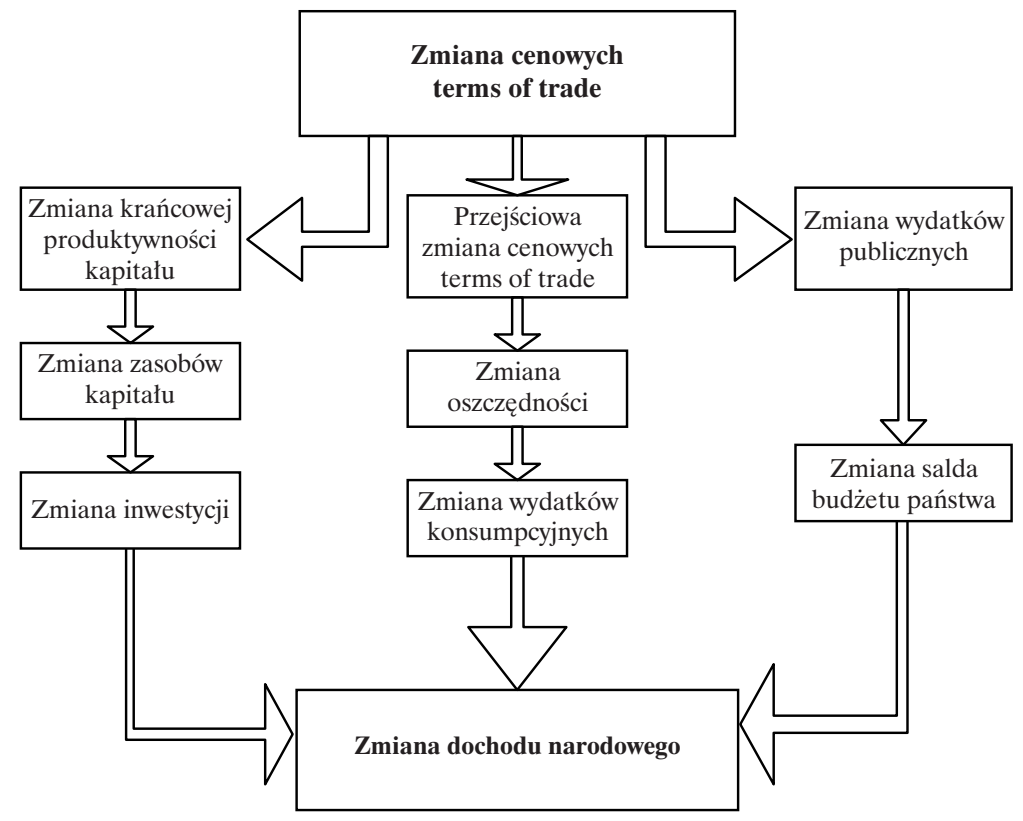

Źródło: opracowanie własne. 
Zmiany terms of trade sa zatem jednym z czynników wyjaśniających pogłębiające się różnice $\mathrm{w}$ dochodach między krajami rozwijającymi się i rozwiniętymi gospodarczo. Ceny towarów eksportowanych przez kraje rozwijające się zazwyczaj charakteryzują się w krótkim okresie dużą zmiennością. Natomiast ceny towarów przemysłowych eksportowanych głównie przez kraje rozwinięte gospodarczo odznaczają się większą stabilnością w krótkim okresie. Stąd, wahania cen towarów eksportowanych przez kraje rozwijające się mogą przyczynić się do wzrostu zmienności krajowej produkcji.

\section{Terms of trade $i$ wzrost gospodarczy w świetle wyników analiz empirycznych}

Literatura ekonomiczna dotycząca współzależności między wzrostem gospodarczym i zmianami terms of trade jest relatywnie uboga, a rezultaty badań bardziej kontrowersyjne, niż te, które dotyczą wpływu zmienności terms of trade na wzrost gospodarczy. W rzeczywistości nie ma dobrze sformułowanej teorii ekonomicznej wyjaśniającej kierunek i stopień oddziaływania terms of trade na wzrost gospodarczy.

Wyniki wielu przeprowadzonych badań wskazują na występowanie dodatniej korelacji między poprawą terms of trade i dynamiką wzrostu gospodarczego. Otóż poprawa terms of trade prowadzi do przyspieszenia wzrostu gospodarczego $\mathrm{w}$ wyniku przyspieszenia akumulacji kapitału w długim okresie (Kose i Reizman, 2001; Deaton i Miller, 1996).

Niektórzy ekonomiści odkryli bardzo istotny wplyw zmian cenowych terms of trade na wzrost gospodarczy (Ghirmay, Sharma i Grabowski, 1999; Mendoza, 1997; Blattman, 2003). Ich zdaniem poprawa terms of trade prowadzi do wyższego poziomu inwestycji i tym samym do przyspieszenia tempa wzrostu gospodarczego.

Bleaney i Greenway (2001) badali związek między zmianami terms of trade i wzrostem gospodarczym w 14 krajach Afryki Subsaharyjskiej w okresie 1980-1995. Wyniki badań ujawniły, że zmienność terms of trade negatywnie oddziałuje na wzrost gospodarczy i inwestycje, zaś poprawa cenowych terms of trade pozytywnie wpływa na wzrost gospodarczy.
Także analizy przeprowadzone przez Grimes (2006) wskazują, że poprawa cenowych terms of trade i niższa zmienność terms of trade przyczyniają się do przyspieszenia wzrostu gospodarczego, zwłaszcza w krajach rozwijających się. Ponadto badania te potwierdziły, że około połowę zmienności dynamiki PKB w Nowej Zelandii od 1960 roku można wyjaśnić zmianami i zmiennością terms of trade tego kraju.

Badania przeprowadzone przez Eichera, Schuberta i Turnovsky'ego (2008) wskazywały, że pogorszenie cenowych terms of trade ma negatywny wpływ na dochód narodowy i dobrobyt. W długim okresie pogorszenie cenowych terms of trade prowadzi jedynie do proporcjonalnego spadku poziomu zadłużenia krajowego, lecz nie przyczynia się do zmian produkcji i inwestycji. Tak więc zmiany cenowych terms of trade wpływają na wzrost gospodarczy wyłącznie w krótkim okresie. Co więcej, wysoka zmienność terms of trade powoduje spadek tempa wzrostu gospodarczego ze względu na powszechną niechęć do ryzyka.

Wyniki wielu analiz empirycznych potwierdziły także, że zmiany cenowych terms of trade wyjaśniają około połowy zmienność produkcji w krajach rozwijających się. Mendoza (1997) analizował oddziaływanie cenowych terms of trade na wzrost gospodarczy w 40 krajach (9 krajów rozwiniętych gospodarczo i 31 krajów rozwijających się) w okresie 1971-1991. Wyniki badań ujawniły występowanie dodatniej korelacji między analizowanymi zmiennymi.

Natomiast Wong (2010) analizował wpływ zmian cenowych terms of trade oraz zmienności terms of trade na wzrost gospodarczy w Japonii i Korei w okresie 1960-2006. Wyniki badań wskazywały, że wzrost zmienności terms of trade prowadził do spadku realnego PKB per capita w obu analizowanych krajach. Zgodnie z rezultatami analizy poprawa cenowych terms of trade i mniejsza zmienność terms of trade są istotnymi czynnikami wzrostu gospodarczego.

Istnieją również dowody empiryczne na poparcie tezy o ujemnej korelacji między poprawą terms of trade i wzrostem gospodarczym w krajach słabo rozwiniętych gospodarczo.

Z kolei Hadass i Williamson (2003) badali związek między terms of trade i wzrostem gospodarczym w krajach rozwi- 
jajacych się w okresie 1870-1940. Udowodnili, że korzystne zmiany terms of trade od 1870 roku do I wojny światowej w krajach eksportujących towary podstawowe przyczyniły się ograniczenia dynamiki wzrostu gospodarczego w tych krajach. Wyniki badań wskazywały także, że zmiany cenowych terms of trade wyjaśniały mniej niż jedną piątą zmian PKB na mieszkańca w tych krajach.

\section{Terms of trade $i$ wzrost gospodarczy w ujęciu modelowym}

W literaturze przedmiotu wykorzystuje się wiele różnych modeli ekonometrycznych, przy pomocy których próbuje się analizować wpływ zmian terms of trade i zmienności terms of trade na wzrost gospodarczy w krajach o różnym poziomie rozwoju gospodarczego. W celu analizy współzależności między terms of trade i wzrostem gospodarczym w Polsce w okresie 1980-2009 wykorzystano w niniejszym opracowaniu model VAR (Vector Autoregression Model) skonstruowany na podstawie modelu Blattman, Hwang i William- son (2003), przedstawiający się poniższym wyrażeniem:

$$
\begin{aligned}
\Delta G D P_{t} & =\sum_{j=o}^{n} \alpha_{j} \Delta G D P_{t-j}+\sum_{j=o}^{n} \gamma_{j} \Delta \text { TOTt }_{t-j}+ \\
& +\sum_{j=o}^{n} \beta_{j} \Delta S D T O T_{t-j}+\mu_{t}
\end{aligned}
$$

gdzie:

$\triangle G D P \quad$ - zmiany $\mathrm{PKB}$ per capita (2000 rok=100);

$\triangle T O T$ - zmiany cenowych terms of trade $(2000$ rok $=100)$;

$\triangle S D T O T$ - zmienność terms of trade mierzona odchylenie standardowym $(2000$ rok=100);

$t \quad-$ okres analizy;

j - rząd opóźnień zmiennych modelu;

$\mu \quad-$ składnik losowy.

Wszystkie przedstawione powyżej zmienne miały częstotliwość roczną i obejmowały okres od 1980 do 2009 roku. Zmiany wskaźników wykorzystanych w modelu przedstawiały się zgodnie z rysunkiem 2 .

Rysunek 2. Dynamika PKB per capita, cenowych terms of trade i zmienności terms of trade $w$ Polsce w okresie 1980-2009 (2000 rok = 100)
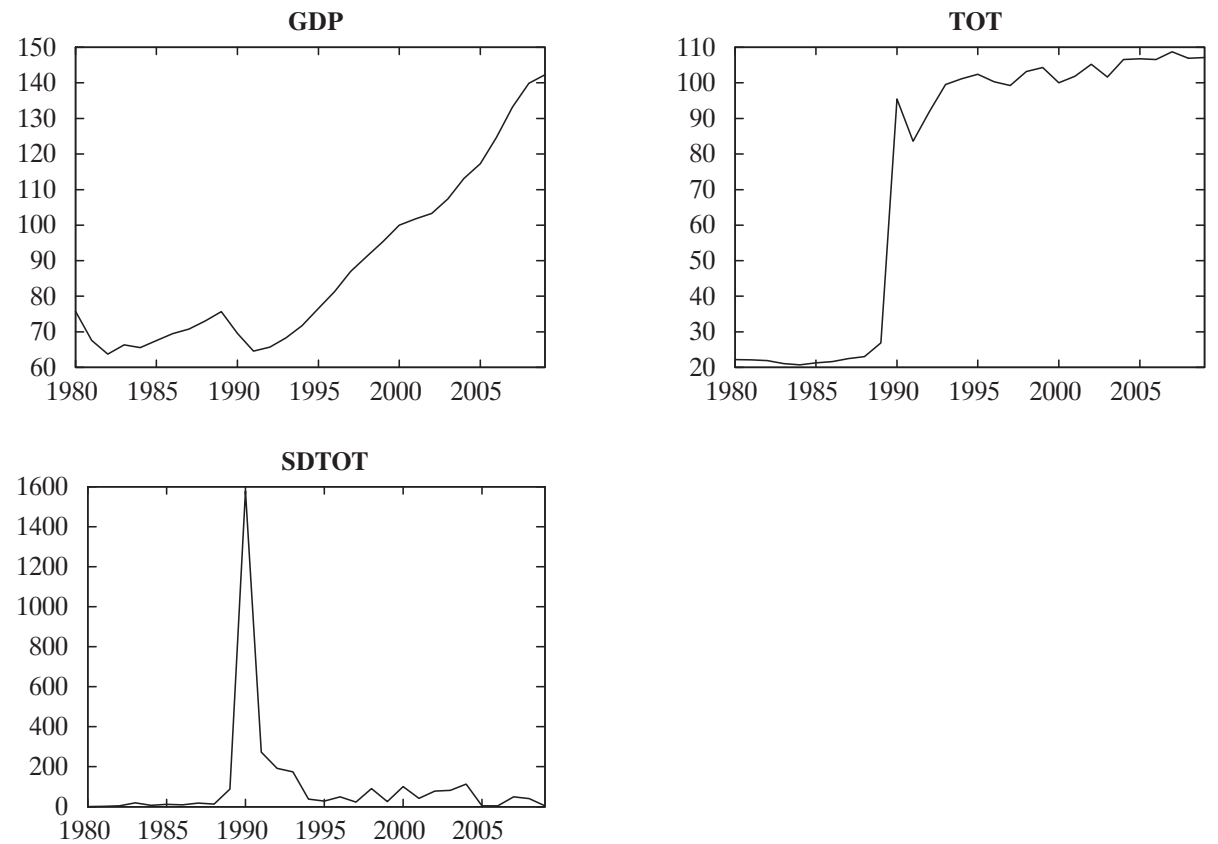

Źródło: Worldbank (2011). 
Wszystkie szeregi czasowe przedstawione na rysunku 2 poddano procedurze logarytmowania, co miało na celu uzyskanie liniowych zależności między analizowanymi zmiennymi. Obliczony na podstawie powyższych danych współczynnik korelacji między dynamiką PKB na mieszkańca i dynamiką terms of trade w okresie 1980-2009 wyniósł 0,63 , co świadczyło o występowaniu istotnej i dodatniej zależności liniowej miedzy zmiennymi. Natomiast obliczony współczynnik korelacji między dynamiką PKB per capita i zmiennością terms of trade w okresie 1980-2009 wyniósł -0,17, co tym razem świadczyło o występowaniu stosunkowo istotnej i ujemnej zależności liniowej między analizowanymi zmiennymi (tabela 1).

Tabela 1. Współczynniki korelacji liniowej dla obserwacji z próby 1980-2009

\begin{tabular}{|l|l|r|l|}
\hline GDP & TOT & SDTOT & \\
\hline 1,0000 & 0,6316 & $-0,1751$ & GDP \\
\hline & 1,0000 & 0,1726 & TOT \\
\hline & & 1,0000 & SDTOT \\
\hline
\end{tabular}

Wartość krytyczna (przy dwustronnym 5\% obszarze krytycznym) $=0,3610$ dla $n=30$

Źródło: opracowanie własne.

Przed dokonaniem estymacji modelu niezbędne było określenie stacjonarności analizowanych szeregów czasowych. W tym celu wykorzystano rozszerzony test Dickeya-Fullera - ADF (Augmented Dickey-Fuller). Wyniki rozszerzonego testu ADF wskazywały na brak stacjonarności wszystkich szeregów czasowych. Wśród analizowanych danych znalazły się szeregi czasowe o rzędach integracji 1 i 2 . Odpowiednie wyniki testów ADF przedstawiono w tabeli 2.

Tabela 2. Wyniki analizy stacjonarności poszczególnych szeregów czasowych modelu VAR

\begin{tabular}{|c|c|}
\hline Szereg czasowy & $\begin{array}{c}\text { Rząd } \\
\text { integracji }\end{array}$ \\
\hline$\triangle G D P$ - zmiany PKB per capita & $\mathrm{I}(1)$ \\
\hline $\begin{array}{c}\Delta T O T-\text { zmiany cenowych terms } \\
\text { of trade }\end{array}$ & $\mathrm{I}(2)$ \\
\hline $\begin{array}{c}\Delta S D T O T \text { - zmienność terms of } \\
\text { trade }\end{array}$ & $\mathrm{I}(2)$ \\
\hline
\end{tabular}

Źródło: opracowanie własne.
W analizie przyjęto trzy okresy opóźnień czasowych między zmiennymi objaśniającymi i zmienną objaśnianą (trzy lata). Wyboru rzędu opóźnień dokonano zgodnie $\mathrm{z}$ wynikami kryteriów informacyjnych modelu Akaike, Schwartza-Bayesiana oraz Hannana-Quinna. Ze względu na brak występowania kointegracji między zmiennymi modelu nie było możliwości rozszerzenia i przekształcenia strukturalnego modelu VAR w wektorowy model korekty błędem (VECM - Vector Error Corection Model).

Kolejnym etapem analizy było oszacowanie parametrów strukturalnych modelu VAR. Na podstawie danych przedstawionych w tabeli 3 można zauważyć, że współczynnik wrażliwości dynamiki PKB na mieszkańca na zmiany cenowych terms of trade wynosił prawie 0,07 przy $1 \%$ poziomie istotności. Zatem wartość tego wspó1czynnika wskazywała na stosunkowo niski i pozytywny wpływ poprawy cenowych terms of trade na tempo wzrostu PKB per capita w Polsce. Natomiast nieco inaczej kształtowała się elastyczność dynamiki PKB per capita na wzrost zmienności terms of trade. Otóż wskaźnik ten wynosił -0,01 przy $1 \%$ poziomie istotności, co wskazywało na stosunkowo niski i ujemny wpływ zmienności terms of trade na dynamikę PKB na mieszkańca w Polsce.

Kolejnym krokiem analizy był pomiar siły oddziaływania zmian cenowych terms of trade i zmienności terms of trade na dynamikę PKB per capita w Polsce w okresie 1980-2009. Pomiaru tego dokonano za pomocą tzw. funkcji odpowiedzi impulsowych (impulse response function), czyli funkcji reakcji PKB per capita na impuls w postaci jednostkowej zmiany poszczególnych czynników determinujących wzrost gospodarczy, tzn. zmian cenowych terms of trade i zmienności terms of trade (rysunek 3).

Zgodnie $\mathrm{z}$ danymi zawartymi na rysunku 3 stwierdzono, że szokowy wzrost PKB per capita o jednostkę prowadził do natychmiastowego wzrostu PKB na mieszkańca w ciagu pierwszego roku od momentu wystąpienia szoku, a w dalszej kolejności do stopniowego spadku dynamiki PKB i stabilizacji po upływie sześciu lat. Odmiennie zaś przedstawiał się wpływ jednorazowego wzrostu cenowych terms of trade na zmianę dynamiki PKB per capita. Otóż poprawa terms of trade prowadziła 


\begin{tabular}{|c|c|c|c|c|c|}
\hline & $\begin{array}{r}\text { Logar } \\
\text { Wyznacznik } n \\
\text { AIC }=-1,0 \\
\text { Test Portmant }\end{array}$ & $\begin{array}{l}\mathrm{tm} \text { wiarygodn } \\
\text { lacierzy kowar } \\
53 \text { BIC }=0 \text {, } \\
\text { eau: } \mathrm{LB}(6)=\end{array}$ & $\begin{array}{l}\text { sci }=40,4591 \\
\text { ncji }=8,9319 \\
712 \text { HQC }= \\
3,5247, \text { df }=2\end{array}$ & $\begin{array}{l}-006 \\
5591 \\
0067]\end{array}$ & \\
\hline & & Równanie & GDP & & \\
\hline & Wspótczynnik & Btad stand. & $t$-Studenta & wartość $p$ & \\
\hline GDP_1 & 0,568295 & 0,179015 & 3,1746 & 0,00554 & $* * *$ \\
\hline GDP_2 & 0,258399 & 0,323243 & 0,7994 & 0,43509 & \\
\hline GDP_3 & $-0,0586462$ & 0,149163 & $-0,3932$ & 0,69908 & \\
\hline TOT_1 & $-0,0048044$ & 0,0223284 & $-0,2152$ & 0,83220 & \\
\hline TOT_2 & 0,0664794 & 0,0181931 & 3,6541 & 0,00196 & $* * *$ \\
\hline TOT_3 & 0,0334645 & 0,0147046 & 2,2758 & 0,03609 & $* *$ \\
\hline SDTOT_1 & $-0,0124817$ & 0,00595721 & $-2,0952$ & 0,05143 & $*$ \\
\hline SDTOT_2 & $-0,00738923$ & 0,00217869 & $-3,3916$ & 0,00347 & $* * *$ \\
\hline SDTOT_3 & $-0,0039288$ & 0,00544298 & $-0,7218$ & 0,48022 & \\
\hline Średn. aryt. & leżnej & 0,029351 & Odch. stand. & zależnej & 0,037320 \\
\hline Suma kwad & eszt & 0,013722 & Bląd standar & $y$ reszt & 0,028411 \\
\hline Wsp. detern & adrat & 0,760185 & Skorygowany & wadrat & 0,647330 \\
\hline $\mathrm{F}(9,17)$ & & 5,987538 & Wartość p dla & tu F & 0,000797 \\
\hline Autokorel. & rho1 & $-0,072286$ & Stat. Durbina & tsona & 2,132145 \\
\hline Test F dla h & o braku restrykc & & & & \\
\hline Wszystkie o & iia zm. GDP & $\mathrm{F}(3,17)=12$ & $62[0,0002]$ & & \\
\hline Wszystkie of & ia zm. TOT & $\mathrm{F}(3,17)=9,3$ & $48[0,0007]$ & & \\
\hline Wszystkie of & nia zm. SDTOT & $\mathrm{F}(3,17)=5,1$ & $98[0,0100]$ & & \\
\hline & & Równanie & TOT & & \\
\hline & Wspótczynnik & Btad stand. & $t$-Studenta & wartość p & \\
\hline GDP_1 & 0,669672 & 1,35443 & 0,4944 & 0,62733 & \\
\hline GDP_2 & 1,38485 & 2,01083 & 0,6887 & 0,50031 & \\
\hline GDP_3 & $-0,538482$ & 0,721874 & $-0,7460$ & 0,46589 & \\
\hline TOT_1 & $-0,137322$ & 0,189559 & $-0,7244$ & 0,47866 & \\
\hline TOT_2 & 0,220016 & 0,188185 & 1,1692 & 0,25848 & \\
\hline TOT_3 & 0,084202 & 0,120351 & 0,6996 & 0,49362 & \\
\hline SDTOT_1 & 0,0567088 & 0,0687543 & 0,8248 & 0,42091 & \\
\hline SDTOT_2 & 0,00490025 & 0,0235458 & 0,2081 & 0,83761 & \\
\hline SDTOT_3 & 0,0377379 & 0,0495267 & 0,7620 & 0,45652 & \\
\hline Średn. aryt. & leżnej & 0,062629 & Odch. stand. & zależnej & 0,251101 \\
\hline Suma kwadr & eszt & 1,429237 & Błąd standar & y reszt & 0,289953 \\
\hline Wsp. detern & adrat & 0,148389 & Skorygowany & wadrat & 0,252370 \\
\hline $\mathrm{F}(9,17)$ & & 0,329128 & Wartość p dla & tu F & 0,953093 \\
\hline Autokorel. 1 & rho1 & $-0,006035$ & Stat. Durbina & tsona & 1,977862 \\
\hline Test F dla h & o braku restryl & & & & \\
\hline Wszystkie of & iia zm. GDP & $\mathrm{F}(3,17)=0,3$ & $566[0,7927]$ & & \\
\hline Wszystkie of & ia zm. TOT & $\mathrm{F}(3,17)=0,5$ & $147[0,6733]$ & & \\
\hline Wszystkie o & aia zm. SDTOT & $\mathrm{F}(3,17)=0,2$ & $502[0,8637]$ & & \\
\hline
\end{tabular}




\begin{tabular}{|l|c|c|c|c|c|}
\hline \multicolumn{7}{|c|}{ Równanie 3: SDTOT } \\
\hline & Wspótczynnik & Btąd stand. & $t$-Studenta & wartość $p$ & \\
\hline GDP_1 & 0,503201 & 11,1432 & 0,0452 & 0,96451 & \\
\hline GDP_2 & $-7,92667$ & 17,2969 & $-0,4583$ & 0,65256 & \\
\hline GDP_3 & 8,15396 & 9,52847 & 0,8557 & 0,40404 & \\
\hline TOT_1 & $-0,187797$ & 1,33416 & $-0,1408$ & 0,88971 & \\
\hline TOT_2 & $-0,552999$ & 1,21444 & $-0,4554$ & 0,65462 & \\
\hline TOT_3 & 0,0437377 & 0,708186 & 0,0618 & 0,95147 & \\
\hline SDTOT_1 & $-0,235335$ & 0,259208 & $-0,9079$ & 0,37662 & \\
\hline SDTOT_2 & $-0,249501$ & 0,302334 & $-0,8252$ & 0,42066 & \\
\hline SDTOT_3 & $-0,160055$ & 0,257721 & $-0,6210$ & 0,54281 & \\
\hline \multicolumn{7}{|l|}{ Średn. aryt. zm. zależnej } & $-0,054214$ & Odch. stand. zm. zależnej & 1,386101 \\
\hline Suma kwadratów reszt & 39,87842 & Błąd standardowy reszt & 1,531597 \\
\hline Wsp. determ. R-kwadrat & 0,171070 & Skorygowany R-kwadrat & $-0,219014$ \\
\hline F(9, 17) & 0,389820 & Wartość p dla testu F & 0,923692 \\
\hline Autokorel. reszt -rho1 & 0,006631 & Stat. Durbina-Watsona & 1,925196 \\
\hline Test F dla hipotezy o braku restrykcji: \\
\hline Wszystkie opóźnienia zm. GDP & $\mathrm{F}(3,17)=0,32965[0,8040]$ \\
\hline Wszystkie opóźnienia zm. TOT & $\mathrm{F}(3,17)=0,11805[0,9483]$ \\
\hline Wszystkie opóźnienia zm. SDTOT & $\mathrm{F}(3,17)=0,43397[0,7314]$ \\
\hline
\end{tabular}

Źródło: opracowanie własne.

Rysunek 3. Funkcje odpowiedzi impulsowych dynamiki PKB per capita na impuls wywołany jednostkową zmianą produktu krajowego brutto na mieszkańca, zmianą terms of trade i zmiennością terms of trade w Polsce
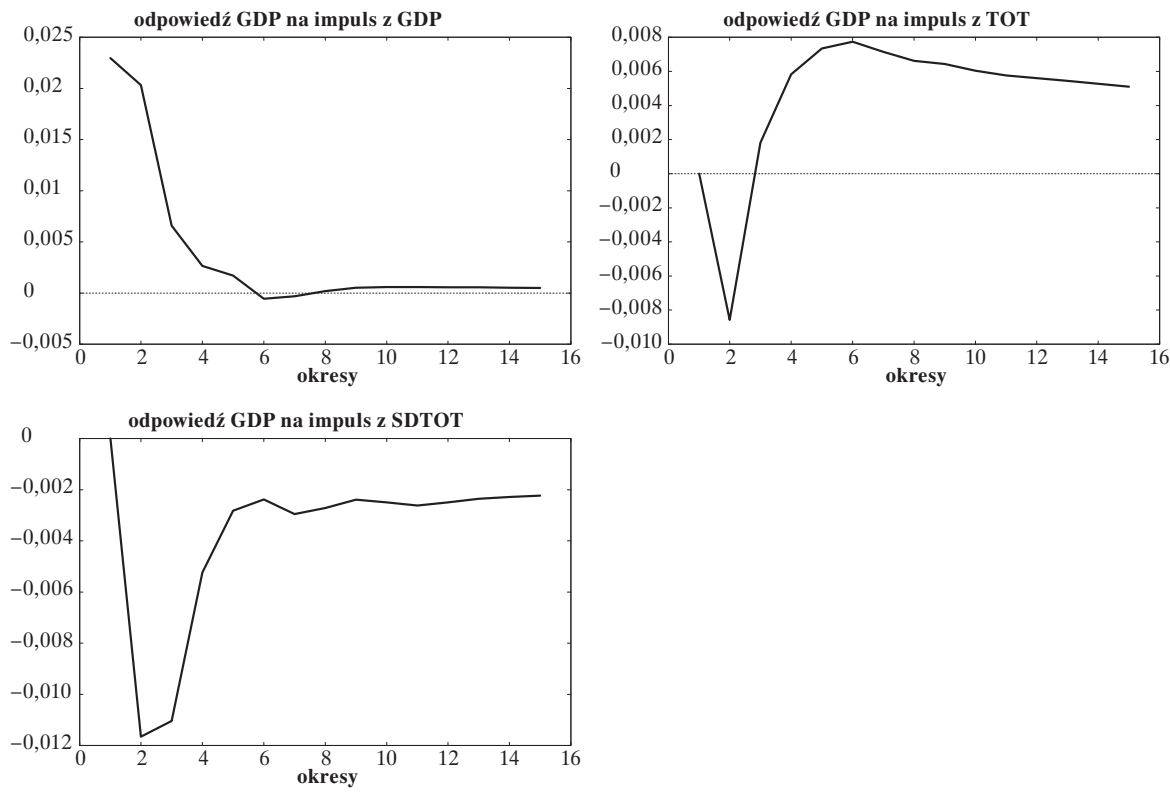

Źródło: opracowanie własne. 
do stopniowego spadku dynamiki PKB na mieszkańca w ciągu dwóch kolejnych lat od wystąpienia szoku, a następnie do wzrostu dynamiki PKB i stabilizacji po upływie sześciu lat. Z kolei wzrost zmienności terms of trade prowadził do gwałtownego spadku dynamiki PKB per capita w ciągu kolejnych dwóch lat od momentu wystąpienia szoku i stabilizacji po upływie sześciu lat.

Ostatnim etapem analizy była dekompozycja wariancji składnika resztowego dynamiki PKB per capita w celu oszacowania wpływu zmian cenowych terms of trade i zmienności terms of trade na kształtowanie się zmienności dynamiki PKB na mieszkańca w Polsce (tabela 4).

Tabela 4. Dekompozycja wariancji dla zmiennej GDP

\begin{tabular}{|c|c|c|c|c|}
\hline Okres & $\begin{array}{c}\text { Błąd } \\
\text { standardowy }\end{array}$ & GDP & TOT & SDTOT \\
\hline 1 & 0,02 & 100,00 & 0,00 & 0,00 \\
\hline 2 & 0,03 & 81,79 & 6,39 & 11,82 \\
\hline 3 & 0,04 & 74,63 & 5,82 & 19,55 \\
\hline 4 & 0,04 & 71,45 & 7,99 & 20,56 \\
\hline 5 & 0,04 & 68,46 & 11,35 & 20,19 \\
\hline 6 & 0,04 & 65,51 & 14,80 & 19,69 \\
\hline 7 & 0,04 & 63,03 & 17,48 & 19,49 \\
\hline 8 & 0,04 & 61,05 & 19,62 & 19,33 \\
\hline 9 & 0,04 & 59,34 & 21,53 & 19,13 \\
\hline 10 & 0,04 & 57,88 & 23,12 & 19,01 \\
\hline 11 & 0,04 & 56,57 & 24,47 & 18,96 \\
\hline 12 & 0,04 & 55,39 & 25,70 & 18,91 \\
\hline 13 & 0,04 & 54,34 & 26,82 & 18,84 \\
\hline 14 & 0,04 & 53,38 & 27,83 & 18,78 \\
\hline 15 & 0,04 & 52,51 & 28,75 & 18,74 \\
\hline
\end{tabular}

Źródło: opracowanie własne.

Zgodnie $\mathrm{z}$ danymi przedstawionymi w tabeli 4 zmiany cenowych terms of trade wyjaśniały ponad $11,3 \%$ zmienności dynamiki PKB na mieszkańca po upływie pięciu lat oraz ponad $28,7 \%$ po upływie piętnastu lat od momentu wystapienia szoku. Z kolei zmiany zmienności terms of trade wyjaśniały około $20 \%$ zmienności dynamiki PKB na mieszkańca po upływie pięciu lat oraz prawie $19 \%$ po uplywie piętnastu lat od momentu wystąpienia szoku. Natomiast największy udział w wyjaśnieniu zmienności dynamiki PKB per capita w Polsce miał czynnik inercyjny, czyli opóźnione zmiany PKB na mieszkańca.

\section{Zakończenie}

Wyniki przeprowadzonych badań potwierdziły, że poprawa cenowych terms of trade w Polsce prowadziła do wzrostu dynamiki PKB per capita w okresie 1980-2009. Wzrost zmienności cenowych terms of trade w Polsce przyczyniał się jednak do zmniejszenia tempa wzrostu PKB na mieszkańca. Co więcej, ujawniono, że zmiany cenowych terms of trade w stosunkowo większym stopniu oddziaływały na dynamikę wzrostu gospodarczego w Polsce niż zmienność terms of trade. Wykazano również, że zmiana cenowych terms of trade i zmienność terms of trade wyjaśniały w zbliżonym stopniu zmienność PKB per capita w Polsce w okresie 1980-2009.

\section{Bibliografia}

Blattman, C., Hwang, J. i Williamson, J.G. (2003). The Terms of Trade and Economic Growth in The Periphery 1870-1983. NBER Working Paper Series, 9940.

Bleaney, M.F. i Greenaway, D. (2001). The impact of terms of trade and real exchange rate volatility on investment and growth in sub-Saharan Africa. Journal of Development Economics, 65.

Deaton, A. i Miller, R.I. (1996). International Commodity Prices, Macroeconomic Performance and Politics in Sub-Saharan Africa. Journal of African Economics, 5.

Eicher, T.S., Schubert S.F. i Turnovsky, S.J. (2008). Dynamic effects of terms of trade shocks: the impact on debt and growth. Journal of International Money and Finance, 27(6).

Grimes, A. (2006). A Smooth Ride: Terms of Trade, Volatility and GDP Growth. New Zealand Ministry of Economic Development Occasional Paper, 4.

Hadass, Y. i Williamson, J. (2003). Terms of Trade Shocks and Economic Performance 1870-1940: Prebisch and Singer Revisited. Economic Development and Cultural Change, 51(3).

Kose, M.A. i Reizman, R. (2001) Trade Shocks and Macroeconomic Fluctuations in Africa. Journal of Development Economics, 65(2).

Mendoza, E. (1997). Terms of Trade Uncertainty and Economic Growth. Journal of Development Economics, 54. 
Prebisch, R. (1950). The Economic Development of Latin American and Its Principal Problems Lake Success. New York: United Nations, Department of Economic Affairs.

Singer, H.W. (1950). The Distribution of Gains between Investing and Borrowing Countries, American Economic Review, 40.
Turnovsky, S.J. i Chattopadhyay, P. (2003). Volatility and growth in developing economies: some numerical results and empirical evidence. Journal of International Economics, 59.

Wong, H.T. (2010). Terms of trade and economic growth in Japan and Korea: an empirical analysis. Empirical Economics, 38. 